\title{
Myofeedback training and intensive muscular strength training to decrease pain and improve work ability among female workers on long-term sick leave with neck pain: a randomized controlled trial
}

\author{
Lotta Dellve • Linda Ahlstrom • Andreas Jonsson • Leif Sandsjö • \\ Mikael Forsman • Agneta Lindegård - Christina Ahlstrand • \\ Roland Kadefors • Mats Hagberg
}

Received: 4 March 2010/Accepted: 4 August 2010/Published online: 28 August 2010

(c) The Author(s) 2010. This article is published with open access at Springerlink.com

\begin{abstract}
The theoretical framework is that muscle tension in the neck is related to insufficient muscular rest and is a risk factor for chronic pain and reduced work ability. Promoting muscle strength and muscle rest may increase work ability and reduce neck pain.

Objectives To test whether myofeedback training or intensive strength training leads to decreased pain and increased work ability in women on long-term sick leave. Methods This is a randomized controlled trial of two 1-month interventions with myofeedback or muscular strength training in the home environment. Female human service organization workers $(n=60)$ on long-term ( $>60$ days) sick leave and with chronic neck pain were followed with self-reported and laboratory-observed data of health, pain, muscular activation, and work ability, at
\end{abstract}

\section{Dellve $(\square)$}

Occupational and Environmental Medicine,

Sahlgrenska Academy, University of Gothenburg,

Box 414, 40530 Gothenburg, Sweden

e-mail: lotta.dellve@amm.gu.se

L. Ahlstrom - A. Jonsson - L. Sandsjö · C. Ahlstrand ·

M. Hagberg

Occupational and Environmental Medicine,

Sahlgrenska Academy, University of Gothenburg,

Medicinaregatan 16, Po 414, 40530 Gothenburg, Sweden

M. Forsman

Division of Occupational and Environmental Medicine,

Department of Public Health Sciences, Karolinska Institutet,

17177 Stockholm, Sweden

A. Lindegård

Institute of Stress Medicine, 41319 Gothenburg, Sweden

R. Kadefors

Department of Work Science, University of Gothenburg,

Box 705, 40530 Gothenburg, Sweden baseline, immediately after the intervention and 3 months after baseline.

Results For both intervention groups, pain was lowered over time compared with the control group. Decreased pain and muscular activity was associated with increased self-rated work ability and with laboratory-observed work ability at 3-month follow-up. Decreased pain was also associated with increased self-rated work ability at 1-month follow-up. Muscular strength training was associated with increased self-rated work ability and mental health. Myofeedback was associated with increased observed work ability and self- rated vitality.

Conclusions The two interventions showed positive results, suggesting that they could be developed for use in health care practice to address pain and work ability. The intensive muscular strength training program, which is both easy to conduct at home and easy to coach, was associated with increased work ability.

Keywords Randomized controlled trial .

Musculoskeletal disorder - Chronic pain · Biofeedback .

Work ability $\cdot$ Sickness absence

\section{Introduction}

Neck pain is one of the most common disorders, with a lifetime prevalence of $45-71 \%$ (Fejer et al. 2006; Mortimer et al. 2006), causing a major part of work disability and longterm sick leave in Sweden (Borg et al. 2001). Musculoskeletal pain and long-term sick leave is higher among women than among men workers (Dellve et al. 2006), and among human service organization workers (HSOs) compared with other occupational groups. The high prevalence of longlasting sick leave due to neck pain among female workers 
stresses the need for intervention methods that are easily applied and can increase work ability and return to work.

The rehabilitation activity among HSO-workers has been low in Sweden. Among the largest group of HSOs, nursing aides and assistants, few (2\%) received occupational rehabilitation and few (3-5\%) returned to work from 2 weeks of sick leave within 30 days (Dellve et al. 2006). A number of studies have reported difficulties in rehabilitation and return to work from long-term sick leave in general and due to neck pain in particular (Savikko et al. 2001; Nielsen et al. 2006; Ekbladh 2008). This point to the need for methods to better support return to work and regained work ability among female workers with musculoskeletal disorder, especially with neck pain. However, work ability is a broad concept comprising the physical, psychological, and social capability of a worker to perform and interact within their work, the individual's specific work demands, health conditions, and mental resources (Ilmarinen and Rantanen 1999; Ludvigsson and Alexandersson 2006). Thus, several dimensions of work ability need to be used to capture the effect of intervention on work ability, e.g. general perception of work ability, muscular strength, vitality, and other dimensions of health (i.e., both self-rated and laboratory assessed).

This randomized control study investigates whether 1 month's intervention with myofeedback through an easyto-wear electromyography (EMG) device, or a short intensive muscular strength training program both coached by an ergonomist at the participants' homes, can increase work ability and decrease pain among female workers on longterm sick leave (exceeding 60 days). The theoretical framework is that muscle tension in the neck is related to insufficient rest, which is a risk factor for chronic pain (Veiersted and Westgaard 1993) and that an intervention that changes the muscle activation pattern will increase health by reducing pain and thereby increasing the work ability. One of the theories for the etiology of neck pain, which may have an association with the muscle activation pattern, is an overload of the low threshold motor units, i.e., the type 1 muscle fibers. At low level continuous load, such as at constrained work without variation, a relative overload may occur of the low threshold motor units that are the type 1 muscle fibers. Female employees with neck pain have also shown to have less muscle rest during work (Hagg and Astrom 1997; Sandsjö et al. 2000). Furthermore, prospective results have shown that perception of muscle tension is a strong risk factor to develop neck pain (Wahlström et al. 2004).

Myofeedback of muscular tension may lead to decreased muscle activation and decreased pain. A method for myofeedback was developed within the "Neuromuscular Assessment in the Elderly Worker" (NEW) project (Hermens and Hutten 2002; Voerman et al. 2007). The myofeedback in this case indicates when the upper part of the trapezius has not had enough time for rest. There are studies that confirm that muscle activation patterns are of importance for developing neck pain. One prospective study found an association between pain in the neck area and a reduction in myoelectric rest periods in the trapezius muscle among female workers (Veiersted and Westgaard 1993). Whether work ability will increase due to myofeedback training is not known.

An established treatment of non-specific pain in neck is strength training (Hartigan et al. 1996; Hurwitz et al. 2008). Composite observations and empirical findings guided our hypothesis of that intensive muscular strength training could lead to decreased muscle activation (Sales 1987; Streepey et al. 2010). Earlier studies have reported associations between intensive muscular strength training and a prolonged relief from neck muscle pain (Andersen et al. 2008a). Moreover, that specific strength training was related to an increased activity level in the pain-inflicted muscle, leading to improved function and pain reduction (Andersen et al. 2008b). Intensive muscular strength training has also been found to be related to an increased function through better nerve muscle coupling and reduced pain through activation of stretch receptors and the release of endorphins (Thoren et al. 1990; Kannus et al. 1992; Hagberg et al. 2000). Based on these results, it is also plausible that strength training may increase work ability by reducing persistent pain and increasing functional capacity among subjects with work-related neck pain. Whether the muscle activation pattern will change due to strength training has not been investigated in earlier studies, but our hypothesis is that changes in activation patterns of the muscles could be one of the mechanisms involved in the self-rated as well as observed increased muscle function.

The overall aim of this randomized controlled trial (RCT) study was to investigate whether rehabilitation of female HSOs on long-term sick leave with chronic neck pain may be facilitated using interventions aimed at changing the activity in the trapezius muscle. A primary aim was to test whether the interventions changed the activity in the trapezius muscle (reported elsewhere). The other primary aim (reported in this study) was to test whether myofeedback training or intensive muscular strength training, through changed muscular activity, is related to decreased pain and increased work ability for women on long-term sick leave.

\section{Study population and method}

\section{Design}

The study design is a RCT, reported according to the CONSORT Statement for Reporting Randomized Trials: Explanation and Elaboration (Altman et al. 2001). Female 
HSOs workers on long-term (>60 days') sick leave and with chronic pain in the neck region were randomized into three groups, namely, myofeedback training, intensive muscular strength training, or control group. The same measurements were repeated, by the same research nurses at a university hospital clinic, 1 and 3 months after start of the intervention.

The study was approved by the ethical committee at the University of Gothenburg and performed in accordance with the ethical standards laid down in the 1964 Declaration of Helsinki and its later amendments. All participants gave their informed consent prior to inclusion in the RCT.

\section{Sample}

The study group consisted of municipality-employed women 35-60 years old with work disability and pain in the neck region for at least 1 year. The inclusion criterion was that the reduction in working degree should be at least $50 \%$ and be due mainly to the diagnoses cervicobrachial pain syndrome (International Classification of Diseases, 10th revision, ICD 10, code M53.1) or cervical pain syndrome (ICD 10-code M54.2), as judged by the treating physician. The work disability was defined as the employed woman being on total or partial $(>50 \%)$ sick leave from work for at least 60 days before inclusion. There was no exclusion due to ongoing rehabilitation measures. Criteria for exclusions were the following: systemic inflammatory diseases, malign diseases and progressive neurologic diseases, psychosis, non-medically treated depressions, and diseases that do not allow hard muscular training.

The participants were selected from a cohort, started in August 2005, of female (35-65-year-old) HSOs employed by one of Sweden's three metropolitan cities (Ahlstrom et al. 2010). Half of the councils within the region, representing various socioeconomic statuses were consecutively invited to the study. All female employees on long-term sick leave $(n=633)$ received written information about the study. Only one reminding letter was sent to nonrespondents. In addition, human resource professionals could invite known employees which they thought met the inclusion criteria $(n=60)$. Only 12 of them fulfilled the inclusion criteria. Of those assessed for eligibility, $82 \%$ participated throughout the study.

Of all respondents in the cohort, 54\% $(n=175)$ had chronic pain in the neck region $(>30 \%$ out of $100 \%$ of the Von Korff index) (Von Korff et al. 1992) and $48 \%$ $(n=154)$ reported having a diagnosed musculoskeletal disorder. The first respondents showing willingness to participate in the RCT study were contacted by phone and informed about the study. The sampling process was consecutive, in the sense that inclusion of councils continued until 20 participants in each group had completed the intervention to at least the 3-month follow-up (Fig. 1). The power calculation was based on estimation of variance in muscle activity and performance tests.

Reasons for withdrawal (voluntarily given) after randomization were the following: lacking motivation $(n=4)$, their doctor advised them to not participate $(n=2)$, own choice due to hassles with myofeedback equipment $(n=4)$, lack of time/had started working full-time $(n=1)$, family reasons/death $(n=1)$, and did not have enough energy to complete the intervention $(n=1)$.

Most participants were 45-54 years old (Table 1). The proportion working in physically demanding jobs were equally distributed among the intervention groups and the control group. In all groups, most participants rated poor work ability, a few rated moderate work ability, and no-one rated good or excellent work ability. Almost every one of the women had had rehabilitation activities such as medical treatments, physiotherapy, and performed own exercise. About half of the women had had contact with a psychologist and one-third had been in contact with complementary medicine (acupuncture, chiropractic and/or naprapathy). About 20\% had had internal occupational rehabilitation at their own work place and about $10 \%$ external occupational rehabilitation. These rehabilitation activities were equally distributed between the intervention groups. There were also a few within the intensive muscular strength training group $(n=8)$, the control group $(n=6)$, and myofeedback training $(n=1)$ which have participated in a multidisciplinary rehabilitation program.

\section{Intervention}

\section{Procedure}

After information about the study, the following measures were performed in randomized order (Latin square randomization): Purdue Pegbord test, Triangle test, Stroop test, and Cutlery wiping performance test. The Triangle test and Stroop test are not part of the current presentation. Participants were randomly selected to intervention groups (concealed randomization). All interventions were directed by an experienced ergonomist, lasted 1 month, and generally took place at the participants' own homes. All participants, including the control group, kept a diary 6 days/ week for 1 month during the intervention period, recording activities, discomfort, pain, and sleeping disturbances. Follow-up measures were performed 1 month (T2) and 3 months (T3) after the intervention start.

\section{Myofeedback training}

Participants used a myofeedback training system made up of a harness, to be worn under the clothes, which included 


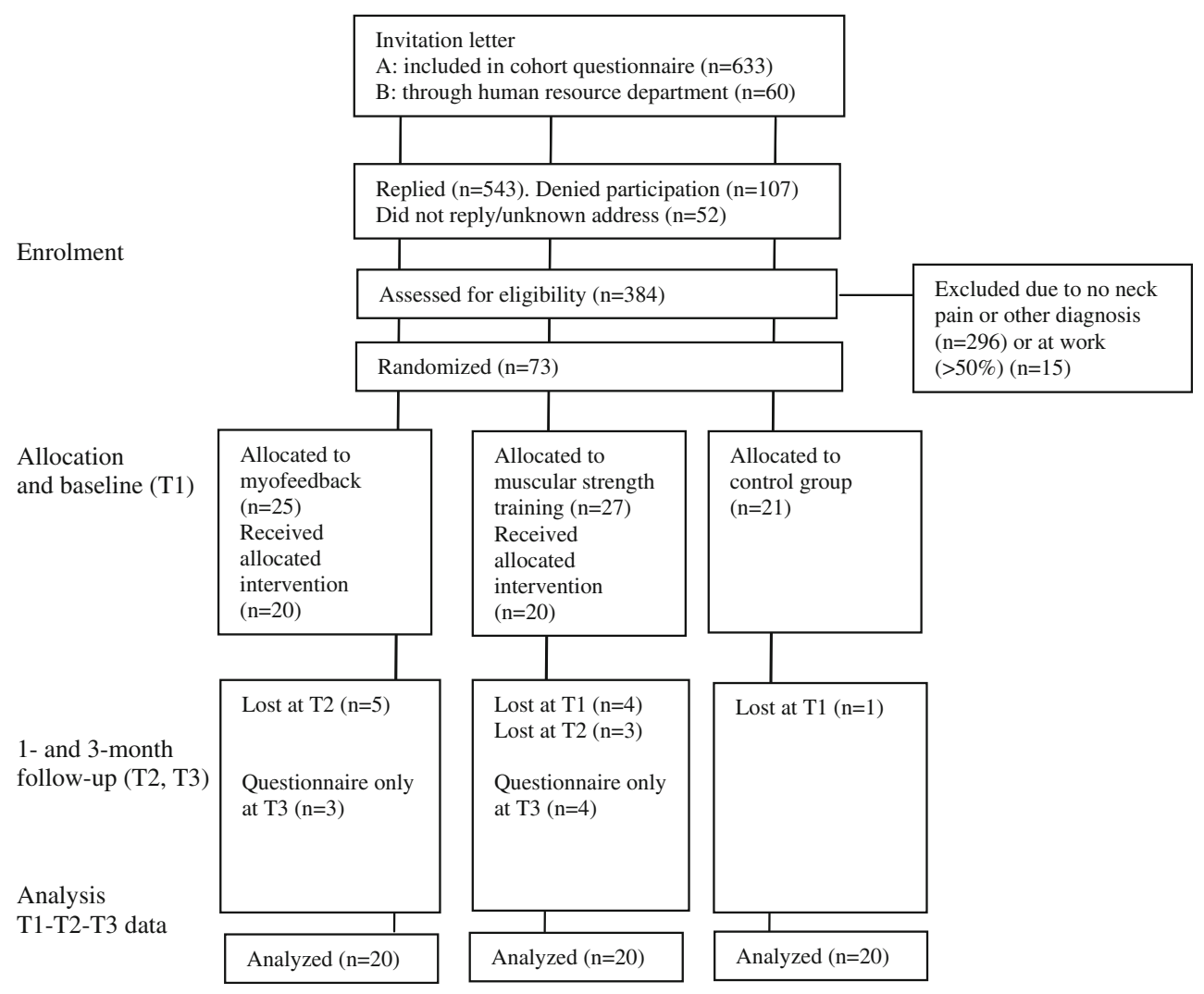

Fig. 1 Diagram illustrating the flow of participants

electrodes. The electrodes registered the muscle activity (EMG) from the upper trapezius muscles on the right and left side. The device analyzes the EMG signal and gives alarm if the shoulder muscles do not reach the preset level of muscular rest time (relative rest time, RRT, i.e., the amount of time the muscle has been at rest). The participants were asked to use the harness for a minimum of $8 \mathrm{~h}$ a week (typically $2 \mathrm{~h}$ for 4 days/week) during various activities throughout the 4 weeks of intervention. The EMG logger and feedback device was carried in a small pouch (Fig. 2). An ergonomist (registered physiotherapist) visited the participants once a week. The ergonomist browsed the recorded EMG profiles on a laptop with reference to the diary entries together with the participant. The discussion focused on situations or sequences with unfavorable muscle activity, with the aim to come up with possible alternative ways to handle such situations.

\section{Intensive muscular strength training}

The participants learned a structured 5-10-minute program to be performed twice a day for 6 days/week. The program began with two warm-up movements, followed by four exercises for strengthening and coordinating the upper extremities (Fig. 3). The last two exercises included breathing and slow down movements. The chosen sample of exercises has been frequently used in similar programs where the aim has been to increase strength in paininflicted muscles. In order to increase the compliance, the participants were "coached" by the ergonomist during the intervention period through personal visits in their homes (twice) and by additional phone calls twice a week.

Questionnaire data

Work ability index (WAI) This is a summary measure of seven dimensions (10 items), Current work ability compared with the lifetime best; Work ability in relation to the demands of the job; Number of current diseases diagnosed by a physician; Estimated work impairment due to disease; Sick leave during the past year (12 months); Own prognosis of work ability 2 years from now; and Mental resources (Ilmarinen et al. 1997; Tuomi et al. 1997). In the analysis, the total score (7-49 points) was used. The classified categories poor (7-27 points), moderate (28-36 points), good (37-43 points), or excellent (44-49 points) (Sjogren-Ronka et al. 2002) were only used for description of the study group.

Single item on work ability Work ability measured with a single item, the global single WAI item "Current work ability compared with the lifetime best", with possible scores of 0 ("completely unable to work") to 10 ("work 
Table 1 Characteristics of the study groups at baseline

\begin{tabular}{|c|c|c|c|c|}
\hline & All $(n)$ & $\begin{array}{l}\text { Myofeedback } \\
\text { training } \\
(n)\end{array}$ & $\begin{array}{l}\text { Strength } \\
\text { training } \\
(n)\end{array}$ & $\begin{array}{l}\text { Control } \\
(n)\end{array}$ \\
\hline \multicolumn{5}{|l|}{ Age group (years) } \\
\hline-44 & 18 & 5 & 7 & 6 \\
\hline $45-54$ & 34 & 15 & 9 & 10 \\
\hline $55-$ & 15 & 4 & 7 & 4 \\
\hline \multicolumn{5}{|l|}{ Type of work } \\
\hline $\begin{array}{l}\text { Care of the elderly } \\
\text { and disabled }\end{array}$ & 31 & 10 & 10 & 11 \\
\hline School and preschool & 27 & 9 & 10 & 8 \\
\hline Social care & 3 & 2 & 1 & \\
\hline Administration & 4 & 2 & 1 & 1 \\
\hline Cleaning & 1 & 1 & - & - \\
\hline \multicolumn{5}{|l|}{ Neck pain $(0-10)$} \\
\hline $9-10$ & 6 & 2 & 3 & 1 \\
\hline $6-8$ & 32 & 11 & 11 & 10 \\
\hline $3-5$ & 23 & 9 & 8 & 6 \\
\hline$<3$ & 5 & 2 & 1 & 2 \\
\hline \multicolumn{5}{|l|}{ Comorbidity } \\
\hline Mental & 34 & 14 & 11 & 9 \\
\hline Cardiac & 6 & 1 & 3 & 2 \\
\hline Pulmonary & 4 & 1 & 2 & 1 \\
\hline \multicolumn{5}{|l|}{ Categories of WAI } \\
\hline Poor (7-27) & 50 & 15 & 17 & 18 \\
\hline Moderate (28-36) & 12 & 7 & 3 & 2 \\
\hline Good (37-43) & - & - & - & - \\
\hline Excellent (44-47) & - & - & - & - \\
\hline
\end{tabular}

ability at its best"), was used as some WAI items are not sensitive to changes over time (de Croon et al. 2005) and the validity of the single item on work ability has been demonstrated (Ahlstrom et al. 2010).

Changed work ability was measured as the difference between the estimated values at different times.

Working degree ranged from 0 to $100 \%$, in steps of $25 \%$, of participants' registered or self-rated working time.

Pain was measured by the instrument developed by Von Korff et al. (Von Korff et al. 1992), a numeric pain scale (0-10) ranging from "no pain" to "worst pain". We used it for the body areas neck and arms/hands/ fingers. For each area, one question about average pain over the previous month was included. Decreased pain was measured as the difference in points between times of measurement.

Self-rated mental health (five items) and vitality (four items) were measured by the Copenhagen Psychosocial Questionnaire (Kristensen et al. 2005). Each 5- and 6 -graded response scale was recalculated to an index of $0-100$ points.

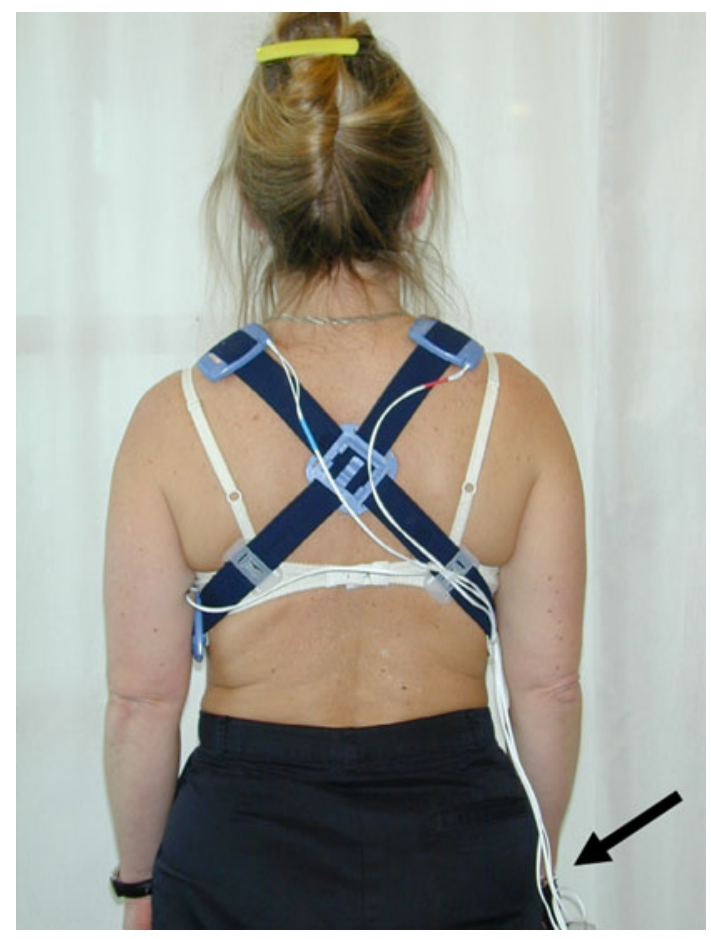

Fig. 2 The harness with embedded electrodes for EMG recording of the upper trapezius. The EMG logger and feedback device was carried in a small pouch (see arrow)

\section{Laboratory-observed tests}

Cutlery wiping performance test was developed to reflect a standardized domestic work task, which all participants could be familiar with, but none had the task included in their normally assignments at work. It measures the number of wiped pieces of cutlery per minute. The test was performed in standing position next to a 90-cm-high bench top. The cutlery was soaked in water and placed in a washing-up bowl; cutlery was wiped one piece at a time and placed in a dry bowl. Participants were instructed to wipe 60 pieces of cutlery at their own pace. The test was developed, piloted, and reliability tested for the purposes of this study (Ahlstrand et al. 2009). A test-retest was performed with twelve female workers. The data were analyzed with Bland and Altman's (1999) limits of agreement test (Bland and Altman 1999). This test gives an indication of individuals own work ability while doing a domestic work task with the upper extremities.

Dexterity/Gross movements of hands, fingers, and arms, and fingertip dexterity were measured using a Purdue Pegboard $^{\circledR}$. The test is to place as many pegs as possible in a vertical row (rows) within $30 \mathrm{~s}$, with their dominant hand.

The maximal grip strength $(\mathrm{kp})$ in the hand was measured by Jamar 5030J1 Hydraulic Hand Dynamometer ${ }^{\circledR}$, right hand, average of three times. 
Fig. 3 Some of the exercises in the intensive muscular strength training programme
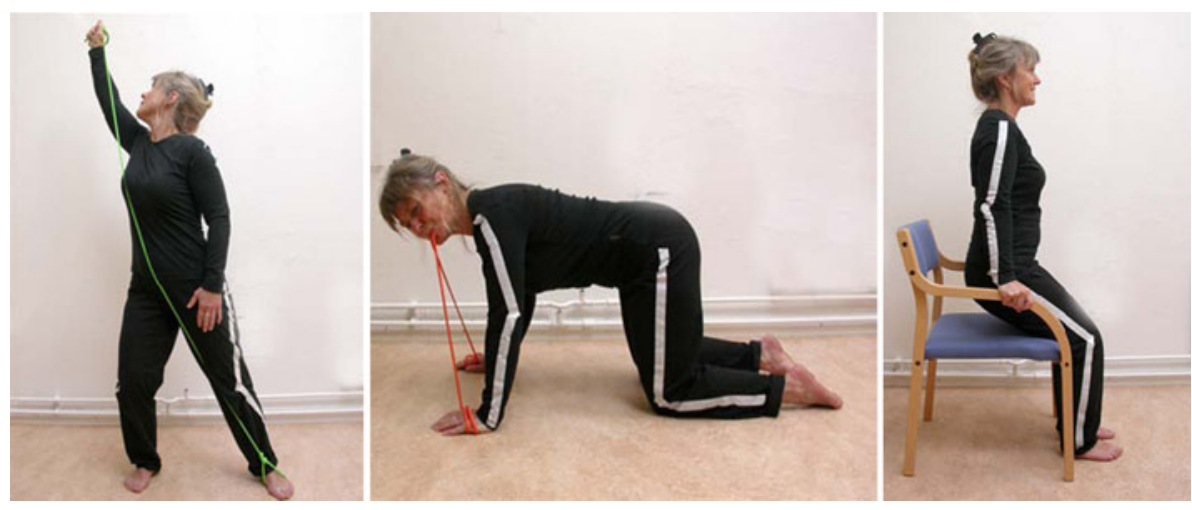

Muscle activity bipolar surface electromyography (sEMG) was collected bilaterally from the descending part of the upper trapezius muscle by means of disposable Ag$\mathrm{AgCl}$ electrodes (Type: N-00-S, Medicotest A/S, Olstykke, Denmark) placed along the direction of the muscle fibers with a center-to-center distance of $2 \mathrm{~cm}$. The electrodes were centered $2 \mathrm{~cm}$ lateral to the midpoint of the line connecting vertebra $\mathrm{C} 7$ and the acromion. The myoelectric signal was recorded with a laptop-based system (Karlsson et al. 2003) and normalized to the mean of three consecutive submaximal reference contractions where the subject held her arms horizontally in the frontal plane. Electrode location, reference contraction, and normalization procedure conformed to recommendations by Mathiassen et al. (1995). To study any changes in muscle activation of relevance in everyday activities as a result of taking part in one of the two interventions, we chose to record sEMG from the trapezius muscle while the subject performed different tasks representing gross motor movements with and without precision demand, a stress-inducing task, as well as the standardized domestic work task in randomized order. The global 10th percentile of the sEMG while performing these tests was chosen to represent the muscle activity and illustrate changes seen from baseline to the follow-ups.

\section{Statistical analysis}

Descriptive statistics for the entire study population, as well as stratified for each intervention group, were calculated at baseline. The change from baseline to first and second follow-up was compared. The association between work ability and decreased pain or decreased muscle activity between different occasions was also assessed. For non-normally distributed data, Wilcoxon's signed rank test was used and for normally distributed data, Student's $t$-test for dependent observation was used. Participants with decreased pain and decreased muscle activity were selected and the change in work ability between baseline and first, as well as second, follow-up was calculated. The dichotomizations of decreased pain and muscle activity resulted in too few participants in each intervention group; thus, the entire study population was compared.

All results with $P$ value $<0.05$ were considered statistically significant.

Longitudinal analysis for repeated measurements with an unstructured covariance matrix was used to assess change between groups over time for WAI items and neck pain (Fitzmaurice et al. 2004). The program PROC MIXED in SAS, version 9.1 (SAS Inc., Cary, NC, USA), was used to implement the analysis method. Data for accessing WAI items and neck pain were considered normally distributed. All statistical analysis was performed using SAS, version 9.1 (Incorporated SI 2004).

\section{Results}

Work ability, health, and pain

\section{Self-rated work ability}

At baseline, the intervention groups did not differ in any self-rated measures $(P<0.05)$. Most subjects $(n=50$, $80 \%$ ) were classified as having poor work ability (Table 1). The mean values of work ability were low in all groups at baseline (Table 2). Among the whole study group, all selfrated dimensions of work ability increased during the study period (Table 2).

\section{Laboratory-observed work ability}

Among the whole study group, the results of the cutlery wiping performance test improved at the follow-up (Table 2).

\section{Self-rated health and pain}

At baseline, most participants rated high pain in the neck region and poor health (Table 1). About $70 \%$ of the participants in the myofeedback group and about $50 \%$ of the 
Table 2 Mean values (m) of pain, health, and work ability before intervention (T1), and differences between baseline values and values at 1 month (T2) and 3 months (T3) after intervention start, tested using Wilcoxon's signed rank test

\begin{tabular}{|c|c|c|c|c|c|c|c|c|}
\hline & \multicolumn{2}{|l|}{$\mathrm{T} 1$} & \multicolumn{3}{|c|}{ Diff T2-T1 } & \multicolumn{3}{|c|}{ Diff T3-T1 } \\
\hline & $m$ & SD & $m$ & SD & $P$ value & $m$ & SD & $P$ value \\
\hline \multicolumn{9}{|l|}{ Self-rated work ability } \\
\hline WAI $(7-49)^{a, b}$ & 19.1 & 7.1 & 2.1 & 5.1 & $0.009 * *$ & 2.4 & 4.5 & $0.001 * *$ \\
\hline Myofeedback training & 19.3 & 7.9 & 2.4 & 5.5 & 0.133 & 1.5 & 3.3 & 0.141 \\
\hline Musc. strength training & 19.0 & 6.9 & 1.5 & 3.4 & 0.076 & 3.9 & 4.8 & $0.005^{* *}$ \\
\hline Control & 19.0 & 6.5 & 2.4 & 6.1 & 0.195 & 2.0 & 5.0 & 0.173 \\
\hline Work ability single item $(0-10)^{\mathrm{a}}$ & 3.2 & 2.4 & 0.5 & 1.8 & 0.070 & 0.8 & 1.9 & $0.003 * *$ \\
\hline Myofeedback training & 3.3 & 2.5 & 0.4 & 2.1 & 0.596 & 0.5 & 1.9 & 0.344 \\
\hline Musc. strength training & 3.3 & 2.5 & 0.5 & 1.7 & 0.278 & 0.9 & 1.5 & $0.039 *$ \\
\hline Control & 3.1 & 2.2 & 0.6 & 1.7 & 0.149 & 1.1 & 2.1 & 0.071 \\
\hline \multicolumn{9}{|l|}{ Laboratory-observed work ability } \\
\hline Cutlery wiping performance (No. of cutlery per min) & 11.1 & 3.9 & 0.5 & 3.2 & 0.057 & 1.2 & 3.6 & $0.025^{*}$ \\
\hline Myofeedback training & 10.5 & 3.6 & 1.1 & 2.8 & $0.036^{*}$ & 0.4 & 3.4 & 0.378 \\
\hline Musc. strength training & 10.7 & 3.8 & 0.1 & 3.6 & 0.985 & 0.2 & 3.3 & 0.903 \\
\hline Control & 12.2 & 4.3 & 0.4 & 3.2 & 0.312 & 2.8 & 3.7 & $0.006^{* *}$ \\
\hline Grip strength & 25.3 & 8.3 & -0.1 & 3.2 & 0.760 & 0.0 & 3.9 & 0.868 \\
\hline Myofeedback training & 25.1 & 9.8 & -0.3 & 3.7 & 0.881 & 0.4 & 4.0 & 0.691 \\
\hline Musc. strength training & 25.5 & 7.3 & 0.5 & 2.9 & 0.561 & 0.5 & 3.5 & 0.463 \\
\hline Control & 25.2 & 7.8 & -0.5 & 3.0 & 0.741 & -0.8 & 4.3 & 0.487 \\
\hline Dexterity/gross movements & 13.8 & 2.4 & 0.5 & 2.0 & 0.070 & 0.2 & 2.1 & 0.484 \\
\hline Myofeedback training & 14.0 & 2.3 & 0.4 & 1.7 & 0.196 & 0.3 & 1.9 & 0.508 \\
\hline Musc. strength training & 13.3 & 2.7 & 0.9 & 2.4 & 0.153 & 0.8 & 2.7 & 0.253 \\
\hline Control & 14.2 & 2.3 & 0.2 & 2.0 & 0.783 & -0.4 & 1.8 & 0.299 \\
\hline \multicolumn{9}{|l|}{ Self-rated health and pain } \\
\hline Mental health $(0-100)^{\mathrm{a}}$ & 51.8 & 22.1 & 6.4 & 21.7 & $0.028 *$ & 6.2 & 22.9 & 0.101 \\
\hline Myofeedback training & 57.7 & 21.5 & 2.2 & 22.0 & 0.818 & -2.1 & 18.4 & 0.492 \\
\hline Musc. strength training & 47.0 & 22.7 & 10.5 & 23.9 & 0.079 & 16.5 & 27.8 & $0.042 *$ \\
\hline Control & 50.4 & 21.5 & 6.7 & 19.3 & $0.032 *$ & 5.4 & 19.5 & 0.310 \\
\hline Vitality $(0-100)^{\mathrm{a}}$ & 36.6 & 19.3 & 3.4 & 17.6 & 0.120 & 7.9 & 20.0 & $0.016^{*}$ \\
\hline Myofeedback training & 36.7 & 19.0 & 6.3 & 16.6 & 0.129 & 10.0 & 15.1 & $0.021^{*}$ \\
\hline Musc. strength training & 35.7 & 20.4 & 2.6 & 21.2 & 0.604 & 12.0 & 26.2 & 0.129 \\
\hline Control & 37.8 & 19.4 & 1.1 & 15.0 & 0.787 & 2.1 & 17.7 & 0.922 \\
\hline Pain in the neck $(0-10)^{\mathrm{b}}$ & 6.1 & 1.9 & -0.1 & 1.6 & 0.661 & 0.3 & 2.1 & 0.388 \\
\hline Myofeedback training & 6.0 & 1.9 & -0.7 & 1.4 & $0.046^{*}$ & -0.1 & 2.0 & 0.795 \\
\hline Musc. strength training & 6.3 & 1.4 & -0.1 & 1.7 & 0.974 & -0.3 & 1.8 & 0.529 \\
\hline Control & 6.2 & 2.5 & 0.5 & 1.6 & 0.292 & 1.1 & 2.2 & $0.046^{*}$ \\
\hline
\end{tabular}

a Baseline measure (T1) varied from 0 to 3 months before intervention start

b $P$ value based on Student's $t$-test due to normally distributed data

$* P \leq 0.05 ; * * P \leq 0.01$

intensive strength training and control group had a comorbidity of mental disorder (self-rated, but diagnosed by a physician) (Table 1).

\section{Working degree}

The mean working degree was at baseline $15 \%$ among intervention groups and $13 \%$ among the controls. In total, the working degree increased to about $30 \%$ at the $1-$ and 3-month follow-up $(P<0.05)$.

Myofeedback intervention

Compared with baseline, the myofeedback intervention group increased their self-rated vitality (at T3) and the laboratory-observed cutlery wiping performance (at T2) 
during the follow-up (Table 2). The working degree increased from 15 to $25 \%$ (T2) and $24 \%$ (T3), but the increase was not significant $(P>0.05)$.

Intensive musculoskeletal strength training intervention

Compared with baseline, the intensive musculoskeletal strength training group increased WAI, single item work ability and self-rated mental health at the 3-month followup. No laboratory-observed tests were significantly $(P<0.05)$ changed. The working degree increased from 15 to $30 \%$ (T2) and 31\% (T3), and the increase was significant $(P<0.05)$ for this group.

\section{Control group}

Among controls, pain in the neck, as well as working activity, was increased at the 3-month follow-up. The working degree increased from 12 to $33 \%$ (T2) and $34 \%$ (T3) $(P<0.05)$.

\section{Longitudinal analysis for repeated measurements}

For neck pain, there was a difference between intervention groups over time $(P=0.0481)$ (Fig. 4). Pain increased in the control group between baseline and T3 (Fig. 4). For the myofeedback group, pain decreased between baseline and $\mathrm{T} 2$. For the muscular strength training group, pain decreased between baseline and T3, compared with the control group.

The mean response for the WAI average across intervention groups changed over time $(P=0.0004)$ (Fig. 5). However, there was no statistically significant difference

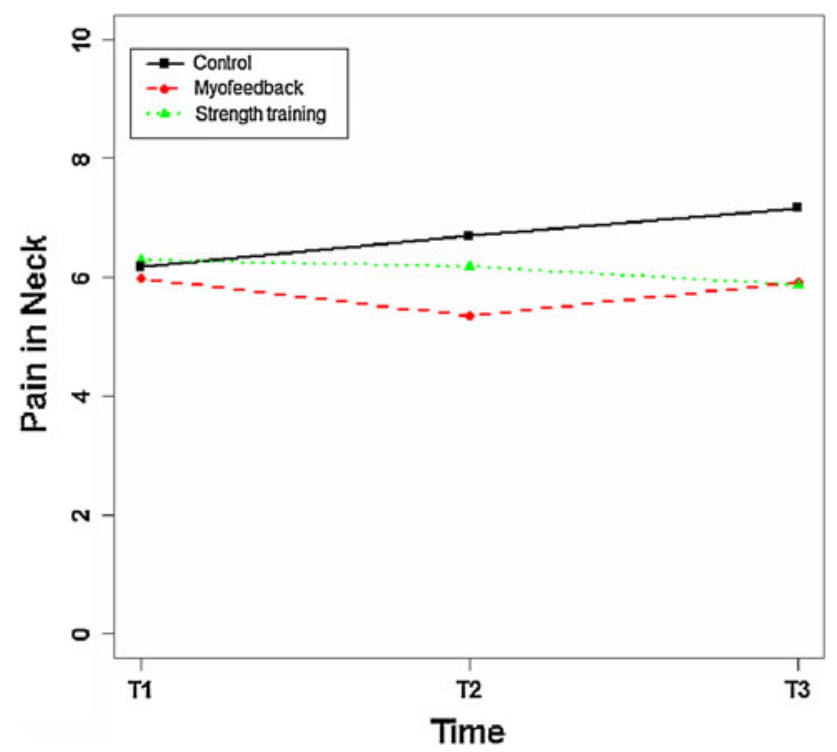

Fig. 4 Adjusted mean for neck pain vs. time for each intervention group

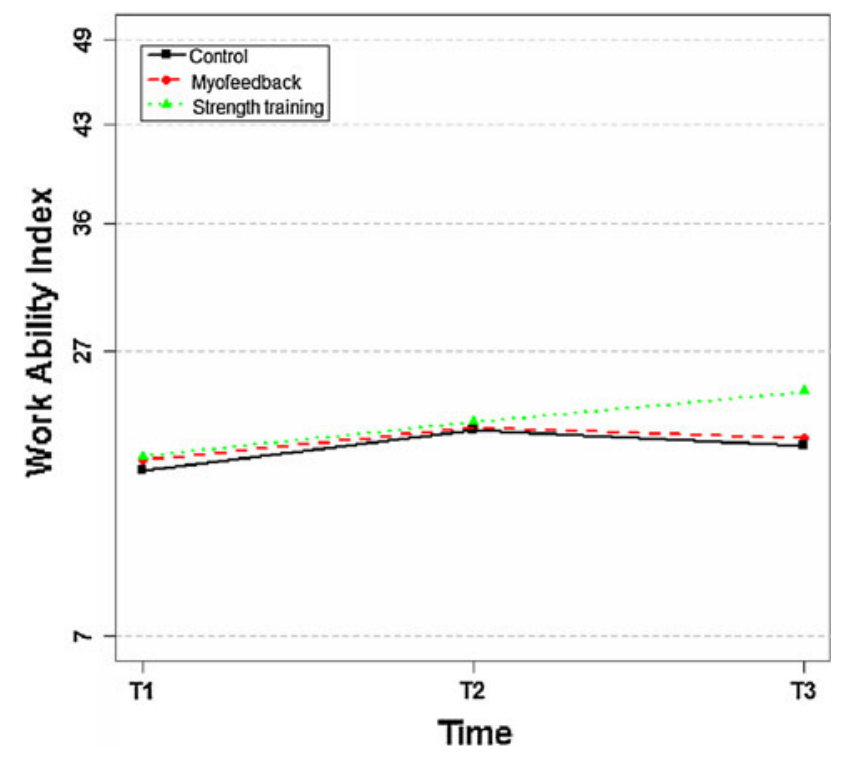

Fig. 5 Adjusted mean for work ability index (WAI) items vs. time for each intervention group

between intervention groups over time (Fig. 5). The control group increased between baseline and the first followup. Both intervention groups increased from baseline to T2, although compared with the control group, there were no improvements.

Effect of decreased pain and decreased muscular activity on changed work ability

Decreased pain was associated with increased work ability (WAI) and indicated for increased dexterity/gross movements at the 1-month follow-up, and with increased cutlery wiping performance at the 3-month follow-up (Table 3). Decreased muscular activity in the trapetzius muscle was associated with increased work ability (WAI) and increased cutlery wiping performance at the 3-month follow-up (Table 3).

\section{Discussion}

The main results of this RCT study are lowered pain at follow-up among both intervention groups in relation to the controls. Decreased pain was associated with increased self-rated and indicated for observed work ability $(P=0.056)$. Both interventions showed positive results among female workers with chronic neck pain on longterm sick leave. Consequently, they could be beneficially developed for use in occupational health or primary care practice to decrease pain and increase work ability. The types of interventions were associated with different outcomes, which may illustrate their various time to effect of 
Table 3 Stratified analysis of changed work ability (self-rated and observed) among participants with decreased pain or muscle activity at the 1-month (T2) and 3-month follow-up (T3)

\begin{tabular}{|c|c|c|c|c|c|c|c|c|}
\hline & \multicolumn{8}{|c|}{ Changed work ability } \\
\hline & \multicolumn{2}{|l|}{ T1 } & \multicolumn{3}{|c|}{ Diff T2-T1 } & \multicolumn{3}{|c|}{ Diff T3-T1 } \\
\hline & $m$ & SD & $m$ & SD & $P$ value & $m$ & SD & $P$ value \\
\hline \multicolumn{9}{|l|}{ Self-rated work ability: WAI } \\
\hline Decreased pain $\mathrm{T} 1-\mathrm{T} 2$ & 18.8 & 7.1 & 3.5 & 5.5 & $0.017 *$ & 1.7 & 4.6 & 0.243 \\
\hline Decreased pain $\mathrm{T} 1-\mathrm{T} 3$ & 20.4 & 6.8 & 0.8 & 5.8 & 0.967 & 1.9 & 4.9 & 0.164 \\
\hline Decreased musc. activity T1-T2 & 19.8 & 6.3 & 2.5 & 6.3 & 0.156 & 2.0 & 4.4 & 0.081 \\
\hline Decreased musc. activity T1-T3 & 19.5 & 6.6 & 1.7 & 5.3 & 0.262 & 2.5 & 4.7 & $0.030 *$ \\
\hline \multicolumn{9}{|c|}{ Observed work ability: Cutlery wiping performance test } \\
\hline Decreased pain $\mathrm{T} 1-\mathrm{T} 2$ & 10.6 & 4.0 & 0.0 & 3.1 & 0.403 & 1.5 & 2.7 & $0.020 *$ \\
\hline Decreased pain T1-T3 & 11.1 & 4.0 & 0.8 & 3.3 & 0.145 & 2.0 & 3.6 & $0.050 *$ \\
\hline Decreased musc. activity T1-T2 & 11.5 & 4.2 & 0.2 & 3.1 & 0.465 & 1.0 & 3.0 & 0.099 \\
\hline Decreased musc. activity T1-T3 & 10.6 & 4.1 & 0.1 & 3.0 & 0.648 & 1.4 & 3.3 & $0.049 *$ \\
\hline \multicolumn{9}{|c|}{ Observed work ability: Dexterity/gross movements test } \\
\hline Decreased pain $\mathrm{T} 1-\mathrm{T} 2$ & 13.4 & 2.8 & 0.9 & 2.1 & 0.056 & 0.4 & 2.9 & 0.517 \\
\hline Decreased pain T1-T3 & 13.3 & 2.6 & 0.6 & 2.2 & 0.275 & 0.7 & 2.2 & 0.249 \\
\hline Decreased musc. activity T1-T2 & 13.9 & 2.0 & 0.5 & 1.8 & 0.118 & 0.4 & 1.9 & 0.181 \\
\hline Decreased musc. activity T1-T3 & 14.0 & 2.3 & 0.3 & 2.0 & 0.461 & 0.3 & 2.0 & 0.407 \\
\hline
\end{tabular}

$* P \leq 0.05$

intervention and sustainability of effect. The results can be generalized to similar groups (regarding health status and societal context), taking into account the below described considerations.

Muscular strength training showed better results in terms of self-rated work ability and mental health. The majority of participating women were employed in care of the elderly and disabled, where requirements regarding mental health and physical fitness are fairly high. Although longer periods of physical training might be needed to reduce chronic pain, the participants were encouraged to continue their training after the intensive program. The positive results may therefore be due to changed behavior. Earlier studies have shown positive results from intensive training program, but there are few studies of how long time of coaching that is needed (Hartigan et al. 1996; Kay et al. 2005, Hurwitz et al. 2008). One review study recommended 4-6 weeks of intensive coaching, followed by 12-18 months of rehabilitation (Hartigan et al. 1996). Studies involving similar target groups have shown that both static strength and muscular endurance increased after an intervention with strength training among women with work-related trapezius myalgia (Andersen et al. 2008a; b). The same study series also indicates that strength training may alleviate pain in patients with trapezius myalgia. Another RCT showed that the threshold for perceived exertion and pain may be increased by muscular strength training (Hagberg et al. 2000).
The myofeedback intervention was associated with increased vitality, increased performance in the cutlery wiping performance test. The results of our study regarding changed muscle activation showed increased gaps in more follow-up test after myofeedback compared to the controls and among participants in the intensive muscular strength training group (L. Sandsjö et al. Effect of myofeedback and intensive strength training on muscle activation in longterm sick listed women with neck pain-a randomized controlled trial. Manuscript). The results regarding the fast changes in muscle activity patterns from a one-month intervention are supported by earlier studies. Two studies of myofeedback showed positive results after 4 weeks training (Hermens and Hutten 2002; Voerman et al. 2007). One study further supported the rapid changes in individual's motor program after being provided visual information (EMG) (Magalhães and Goroso 2009). The significant increase in working activity in the muscular strength training group and among controls was not found in this group. The associations with decreased performance regarding working activity could be interpreted as changed behavior regarding rest taking. Or, if changed muscle activity would affect work ability, a longer period of follow-up to capture possible changes may be needed.

Over time, the pain was lowered in the intervention groups compared with the control group. The perceived pain increased steadily among the controls. The result for the control group can illustrate what would have happened 
if there had been no intervention. Decreased pain was related to increased self-rated work ability (WAI) and laboratory-tested work ability (Cutlery wiping performance test and Purdue Pegboard (gross movement/dexterity test)) at the 1- or 3-month follow-up. Earlier studies of the associations between pain and work disability have been inconsistent and moderated by emotional functions (de Croon et al. 2004). This may be due to individuals' potential of coping with pain for sustained life functions. Neither of the performed EMG-tests of muscle activity showed consistent change in all the evaluated parameters for any of the tests (L. Sandsjö et al. Effect of myofeedback and intensive strength training on muscle activation in long-term sick listed women with neck pain-a randomized controlled trial. Manuscript). The stratified analysis, in the present study, among participants with decreased muscle activity, showed that work ability (regarding WAI and wiping cutlery performance test) increased at the threemonth follow-up (T3). It is possible that, a longer period of follow-up would be necessary to capture the possible changes. The relatively modest improvements in work ability and decrease in pain should be viewed in relation to the difficulties in rehabilitation of individuals with long duration of sick leave (Dellve et al. 2002, 2006; Nielsen et al. 2006; Ekbladh 2008; Holmgren 2008). The clinical significance of the changes of work ability can be discussed. Earlier studies have regarded changes in WAI exceeding 2 points, as clinically relevant (Tuomi et al. 1997). When comparing the groups, muscular strength training increased most, about four points, which could be regarded as clearly clinical significant. Both decreased pain and decreased muscular activity was related to increases in WAI of 4.4-4.9 points, which also could be regarded as clinically relevant.

This RCT study met several challenges but succeeded in recruiting compliance to the intervention and in following 60 female workers on long-term sick leave for two followups. The time period of recruiting participants had to be extended due to participants' various needs of changing time for measures and due to dropouts during the intervention period. Several earlier RCT studies, reported and not reported, had major difficulties in recruiting and following voluntary workers on long-term sick leave, and in completing an RCT study. We had the intention to make the two intervention programs as attractive as possible to assure high compliance and attendance, as well as a close and easy access to the interventionist; this is more of an issue with long-term intervention programs, these ones lasting for four weeks. Noteworthy is that good compliance can result in an overestimation of the treatment effect. The control group did not have this contact. However, the length of the visit with the research nurses, the amount of information given and efforts were taken to achieve a similar overall atmosphere for all participants for the three groups at the three different occasions.

Dropouts were slightly higher in the myofeedback training group. Perceived problem with myofeedback equipment was the main reported reason. Another possible reason may have been the higher proportion of mental comorbidity in this group, which has been related to length of sick leave (Hensing et al. 1997; Savikko et al. 2001). Most (67\%) dropouts during the intervention also had a mental disorder as comorbidity. In order to keep the participants from dropping out, we believe it was important for the intervention to be easy to conduct, for it to take place in the participants' own homes, and for there to be flexibility in providing times for follow-up measurements and in access to, and support from, the study coordinator and interventionist. All participants had a lot of earlier experience of rehabilitation activities, which types were also rather equally distributed between the groups. Further, they were still on long-term sick leave and we could therefore not control for its influence.

Regarding the statistics, due to the number of participants and non-normally distributed data, the change from baseline to first and second follow-up was assessed through differences between the measuring occasions. In order to increase power in the analysis, a longitudinal analysis method with repeated measurements was used for the WAI items and neck pain, since data were considered normally distributed. Due to the low number of participants, unadjusted analysis was performed. Furthermore, potential confounders and interaction in relation to WAI items and neck pain are not considered. Both analysis methods indicate similar results although the longitudinal analysis method uses more information compared with Student's $t$-test for dependent observations. However, since the number of observation declines over time, results from the longitudinal analysis are considered to be more consistent.

\section{Conclusions}

Both interventions showed positive results among female workers with chronic neck pain on long-term sick leave, so they could be further developed for use in occupational health service or primary care practice to address pain and work ability. The intensive strength training program, which is both easy to conduct at home and easy to coach, was associated with increased self-rated work ability and improved mental health among female workers on longterm sick leave. The effect of myofeedback was reduced pain immediately after the intervention and improved vitality. Decreased pain was associated with increased selfrated and laboratory-observed work ability. 
Acknowledgments The authors would like to thank physiotherapist Lena Grundell for conducting the interventions. We are grateful to the Swedish Council for Working Life and Social Research for financial support.

Conflict of interest The authors declare that they have no conflict of interest.

Open Access This article is distributed under the terms of the Creative Commons Attribution Noncommercial License which permits any noncommercial use, distribution, and reproduction in any medium, provided the original author(s) and source are credited.

\section{References}

Ahlstrand C, Dellve L, Ekman A, Jonsson A, Ahlstrom L, Hagberg M (2009) Cutlery wiping performance test. Occupational and Environmental Medicine at University of Gothenburg, Sweden: report no 124. University of Gothenburg, Sweden

Ahlstrom L, Grimby-Ekman A, Hagberg M, Dellve L (2010) The work ability index and single-item question: associations with sick leave, symptoms, and health - a prospective study of women on long-term sick leave. Scand J Work Environ Health, Apr 7. [Epub ahead of print]

Altman DG, Schulz KF, Moher D, Egger M, Davidoff F, Elbourne D et al (2001) The Revised CONSORT Statement for Reporting Randomized Trials: Explanation and Elaboration. Ann Intern Med 134:663-694

Andersen L, Kjaer M, Sogaard K, Hansen L, Kryger A, Sogaard G (2008a) Effect of two contrasting types of physical exercise on chronic neck muscle pain. Arthritis Rheum 15:84-91

Andersen L, Andresen C, Zebis M, Nielsen P, Sogaard K, Sjogaard G (2008b) Effect of physical training on function of chronically painful muscles: a randomizied controlled trial. J Appl Physiol 105:1796-1801

Bland JM, Altman DG (1999) Measuring agreement in method comparison studies. Stat Methods Med Res 8:135-160

Borg K, Hensing G, Alexanderson K (2001) Predictive factors for disability pension-an 11-year follow up of young persons on sick leave due to neck, shoulder, or back diagnoses. Scand J Public Health 29:104-112

de Croon EM, Sluiter JK, Nijssen TF, Dijkmans BAC, Lankhorst GJ, Frings-Dresen MHW (2004) Predictive factors of work disability in rheumatoid arthritis: a systematic literature review. Ann Rheum Dis 63:1362-1367

de Croon EM, Sluiter JK, Nijssen TF, Kammeijer M, Dijkmans BAC, Lankhorst GJ, Frings-Dresen MHW (2005) Work ability of Dutch employees with rheumatoid arthritis. Scand J Rheumatol 34:277-283

Dellve L, Lagerstrom M, Hagberg M (2002) Rehabilitation of home care workers: supportive factors and obstacles prior to disability pension due to musculoskeletal disorders. J Occup Rehabil 12:55-64

Dellve L, Karlberg C, Allebeck P, Herloff B, Hagberg M (2006) Macro-organizational factors, the incidence of work disability, and work ability among the total workforce of home care workers in Sweden. Scand J Public Health 34:17-25

Ekbladh E (2008) Return to work, Assessment of subjective psychosocial and enviromental factors. Dissertation. Department of Social and Welfare studies, Linköping University, sweden

Fejer R, Kyvik KO, Hartvigsen J (2006) The prevalence of neck pain in the world population: a systematic critical review of the literature. Eur Spine J 15:834-848
Fitzmaurice G, Laird N, Ware J (2004) Applied Longitudinal analysis. John Wiley \& Sons, New Yearsy

Hagberg M, Harms-Ringdahl K, Nisell R, Hjelm EW (2000) Rehabilitation of neck-shoulder pain in women industrial workers: a randomized trial comparing isometric shoulder endurance training with isometric shoulder strength training. Arch Phys Med Rehabil 81:1051-1058

Hagg GM, Astrom A (1997) Load pattern and pressure pain threshold in the upper trapezius muscle and psychosocial factors in medical secretaries with and without shoulder/neck disorders. Int Arch Occup and Environ Health 69:423-432

Hartigan C, Miller L, Liewehr SC (1996) Rehabilitation of acute and subacute low back and neck pain in the work-injured patient. Ortophed Clin North Am 27:841-860

Hensing G, Spak F, Alexanderson K, Allebeck P (1997) Sick-leave among women and the role of psychiatric disorder. Scand J Soc Med 25:185-192

Hermens HJ, Hutten MMR (2002) Muscle activation in chronic pain: its treatment using a new approach of myofeedback. Int $\mathrm{J}$ Ind Ergonom 30:325-336

Holmgren K (2008) Work-related stress in women-assessment, prevalence and return to work. Dissertation. Sahlgrenska Academy, University of Gothenburg, Sweden

Hurwitz EL, Carragee EJ, van der Velde G, Carroll LJ, Nordin M, Guzman J, Peloso PM, Holm LW, Cote P, Hogg-Johnsson S, Cassidy JD, Haldeman S (2008) Treatment of neck pain: noninvasive interventions: results of the bone and joint decade 2000-2010 task force on neck pain and its associated disorders. Spine 15:S123-S152

Ilmarinen J, Rantanen J (1999) Promotion of work ability during ageing. Am J Ind Med Suppl 1:21-23

Ilmarinen J, Tuomi K, Klockars M (1997) Changes in the work ability of active employees over an 11-year period. Scand J Work Environ Health 23(Suppl 1):49-57

Incorporated SI (2004) SAS 9.1. SAS/Stat user's guide, version 9.1. Cary, NC, USA

Kannus P, Jozsa L, Kvist M, Lehto M, Jarvinen M (1992) The effect of immobilization on myotendinous junction: an ultrastructural, histochemical and immunohistochemical study. Acta Physiol Scand 144:387-394

Karlsson JS, Bäcklund T, Edström U (2003) A new wireless multichannel data system for acquisition and analysis of physiological signals. Paper presented at seventeenth international symposium on biotelemetry, Brisbane, Australia

Kay TM, Gross A, Goldsmith C, Santaguida PL, Hoving J, Bronfort G (2005) Exercises for mechanical neck disorders. Cochrane Database Syst Rev, 20, doi:10.1002/14651858.CD004250.pub3

Kristensen T, Hannerz H, Høgh A, Borg V (2005) The Copenhagen Psychosocial Questionnaire-a tool for the assessment and improvement of the psychosocial work environment. Scand J Work Environ Health 31:438-449

Ludvigsson M, Alexandersson K (2006) Begreppet arbetsförmåga en litteraturgenomgång [The concept work ability-a literature review]. Arbete och Hälsa

Magalhães F, Goroso D (2009) Preparatory EMG activity reveals a rapid adaptation pattern in humans performing landing movements in blindfolded condition. Percept Mot Skills 109:500-516

Mathiassen SE, Winkel J, Hagg GM (1995) Normalization of surface EMG amplitude from the upper trapezius muscle in ergonomic studies-A review. J Electromyography and Kinesiol 5:197-226

Mortimer M, Pernold G, Wiktorin C (2006) Low back pain in a general population. Natural course and influence of physical exercise-a 5-year follow-up of the Musculoskeletal Intervention Center. Spine 31:3045-3051

Nielsen M, Rugulies R, Christensen K, Smith-Hansen L, Kristensen T (2006) Psychosocial work environment predictors of short and 
long spells of registered sickness absence during a 2-year follow up. J Occup Environ Med 48:591-598

Sales G (1987) Influence of exercise and training on motor unit activation. Exerc Sport Sci Rev 15:95-151

Sandsjö L, Melin B, Rissen D, Dohns I, Lundberg U (2000) Trapezius muscle activity, neck and shoulder pain, and subjective experiences during monotonous work in women. Eur J Appl Physiol $83: 235-238$

Savikko A, Alexanderson K, Hensing G (2001) Do mental health problems increase sickness absence due to other diseases? Soc Psychiatry Psychiatr Epidemiol 36:310-316

Sjogren-Ronka T, Ojanen MT, Leskinen EK, Tmustalampi S, Malkia EA (2002) Physical and psychosocial prerequisites of functioning in relation to work ability and general subjective well-being among office workers. Scand J Work Environ Health 28:184-190

Streepey JM, Mock MJ, Riskowski JL, Vanwye WR, Vitvisky BM, Mikesky EA (2010) Effects of quadriceps and hamstrings proprioceptive neuromuscular facilitation stretching on knee movement sensation. J Strengh and cond res 24:1037-1042
Thoren P, Floras JS, Hoffmann P, Seals DR (1990) Endorphins and exercise: physiological mechanisms and clinical implications. Med Sci Sports Exerc 22:417-428

Tuomi KJ, Ilmarinen J, Martikainen R, Aalto L, Klockars M (1997) Aging, work, life-style and work ability among Finnish municipal workers in 1981-1992. Scand J Work Environ Health 23:58-65

Veiersted KB, Westgaard RH (1993) Development of trapezius myalgia among female workers performing light manual work. Scand J Work Environ Health 19:277-283

Voerman GE, Sandsjö L, Vollenbroeck-Hutten M, Larsman P, Kadefors R, Hermens H (2007) Effects of ambulant myofeedback training and ergonomic counselling in female computer workers with work-related neck-shoulder complaints: a randomized controlled trial. J Occup Rehabil 17:137-152

Von Korff M, Ormel J, Keefe FJ, Dworkin SF (1992) Grading the severity of chronic pain. Pain 50:133-149

Wahlström J, Hagberg M, Toomingas A, Wigaeus Tornqvist E (2004) Perceived muscular tension, job strain, physical exposure, and associations with neck pain among VDU users: a prospective cohort study. Occup Environ Med 61:523-528 